TRABALHOS LIVRES EIXO 1:

“A CLÍNICA EM MOVIMENTO" 


\title{
A potencialidade da escuta analítica em tempos inquietantes 76
}

\author{
Adriana Silveira Gobbi77 \\ Daniela Weber Bratz 78 \\ Diorge Augusto Guedes Mariano 79 \\ Magda Luisa Dedavid Nunes 80 \\ Sissi Vigil Castiel ${ }^{81}$
}

No dia 14 de maio de 2020, a Organização das Nações Unidas (ONU) chamou a atenção para a importância da saúde mental no momento em que vivemos, ressaltando que o impacto e os efeitos da Pandemia da COVID-19 não se dão apenas em termos físicos, mas também psíquicos (https://nacoesunidas.org/oms-o-impacto-da-pandemia-na-saudemental-das-pessoas-ja-e-extremamente-preocupante/).

De fato, não está em questão a interrupção do nosso trabalho neste momento e, tendo em vista que nós analistas atendemos preferencialmente de forma presencial, surge a interrogação de como vai se sustentar o fazer analítico em termos de seus fundamentos, prescindindo da presença física do paciente e do analista.

On-line ou presencial, a psicanálise sempre esteve diante de impasses para seguir existindo, de forma a dar conta da necessidade de repensar seus alicerces frente a mudanças nas subjetividades ou na cultura. Mais uma vez estamos colocados em questão, o que pode se constituir em uma oportunidade para se pensar os movimentos da clínica.

O processo analítico baseia-se na transferência, esta tem origem na sexualidade infantil e dirige-se ao analista. Freud (1912/1989) diz que o paciente chega à análise com ideias libidinais antecipadas, portanto ser objeto da

\footnotetext{
${ }^{76}$ Apresentado em Trabalhos livres no II Simpósio Bienal SBPSP "Fronteiras da Psicanálise: a clínica em movimento" no dia 21 de agosto de 2020.

77 Psicóloga. Mestre em Psicologia Clínica pela Pontifícia Universidade Católica do Rio Grande do Sul (PUCRS), Porto Alegre/RS.

78 Psicóloga. Psicanalista. Membro efetivo da Sigmund Freud Associação Psicanalítica, Porto Alegre/RS.

79 Psicólogo. Psicanalista em formação e membro associado da Sigmund Freud Associação Psicanalítica, Porto Alegre/RS.

80 Psicóloga. Especialista em Teoria Psicanalítica pelo Instituto Contemporâneo de Psicanálise e Transdisciplinaridade, Porto Alegre/RS.

${ }^{81}$ Psicanalista. Doutora em Psicanálise pela Universidade Autônoma de Madri. Membro pleno da Sigmund Freud Associação Psicanalítica, Porto Alegre/RS.
} 
transferência é ser alvo da sexualidade infantil do paciente. Tendo isso em vista, como se poderia prescindir da presença física para que a análise se desenvolva? O trabalho que estamos efetuando, neste momento, é analítico?

Essas questões nos levaram a pensar nos elementos técnicos que seriam imprescindíveis para fundamentar nosso ofício no atual contexto. O que nos reporta aos postulados de André Green que propôs modificações na técnica diante dos pacientes de fronteira, quando o processo de simbolização se encontrava impossibilitado e o método tradicional não alcançava transformações efetivas. Ainda que o trabalho que realizamos hoje não se refira somente a esses pacientes, os conceitos de Green, tais como enquadre, contratransferência e capacidade de devaneio podem trazer potencialidades à escuta.

Dadas as diferenças das condições do setting atualmente, em que muitas vezes ficamos reduzidos ao áudio ou a uma pequena tela, iniciamos esse breve percurso com um conceito que trata de potencialidades e ampliações técnicas - a capacidade de devaneio, de Bion. Ele afirma que, ao nascer, a criança funciona a partir de um modelo digestivo; o psiquismo se ancora neste modelo. No entanto, a experiência com o seio bom não é suficiente para engendrar o pensamento. Dessa forma, a mãe digere psiquicamente, o que não é possível para a criança assimilar e devolve o produto metabolizado por ela, ajudando, assim, a constituir o psíquico da criança graças à sua função ligadora.

Green (2001) utiliza essa formulação de Bion para teorizar a respeito dos pacientes de fronteira, nos quais a capacidade de devaneio da mãe fracassou e, portanto, é uma necessidade que esta esteja presente no analista. O autor afirma que este último não é a mãe, pois nessa relação, não há o contato físico tal como a mãe e o bebê, somente nos elementos materiais da análise, o divã, o espaço reservado, o tempo concedido, que estão longe de equivaler ao contato físico da mãe com a criança. No entanto, parte desta comparação ao afirmar que a função ligadora deve estar presente no analista, abrindo caminho para a simbolização ausente no paciente. Entendemos que nem todos os analisandos que vamos atender on line tenham esse prejuízo representacional, mas dadas as condições restritas do setting, nosso lugar não pode prescindir da função ligadora e da capacidade de devaneio. Por isso, a importância de utilizá-la como um dos elementos para pensar o atendimento remoto. 
De fato, sem a presença libidinal do corpo, focalizado apenas na fala, o analista precisa estar mais atento ao escutar e imaginarizar as nuances das associações. Destacando-se os enunciados verbais, não se estaria colocando em evidência um dos aspectos centrais de toda análise? Além disso, sempre é bom lembrar a contingência dos objetos aos quais a libido investe. Nesse sentido, poderíamos pensar que a libido antes investida no corpo do analista agora está investida na sua voz, portanto, mantendo-se este como objeto da transferência.

Sendo assim, nos perguntamos se não seria interessante, neste momento onde os aspectos corporais estão mais ausentes, que o analista pudesse escutar elevando a potência simbólica que comportam as palavras e utilizar da sua capacidade de devaneio frente à própria contratransferência. Entendendo-se esta como constituída por todo seu funcionamento mental, para além dos efeitos positivos ou negativos da transferência do analisando (Green, 2008).

A respeito da potência da palavra, quando Green (2017) descreve a transferência define-a como um ato duplo: sobre a palavra e sobre o objeto. Em relação à primeira, o autor diz que esta é habitada pela força e que, portanto, não pode ser reduzida somente ao sentido. Assim, os movimentos psíquicos abrem caminho através dela na qualidade de afeto e encontram, por esse meio, o seu lugar de expressão. Estes aspectos nos levam à ideia de uma potencialidade presente na escuta, tendo em vista que o discurso analítico é a relação entre duas falas que não pertencem nem ao real nem ao imaginário em sua totalidade, pois se caracterizam também por ser um discurso de relações potenciais, que encontram nos afetos e nas palavras sua via de manifestação.

A escuta psicanalítica parte da compreensão do sentido manifesto do discurso do paciente, para então poder realizar o trabalho de imaginarizá-lo. Ao escutar, o analista desliga a sequência linear desta cadeia e evoca fragmentos de sessões anteriores, recombinando os elementos. Neste sentido, Green (2001) agrega a esse processo a utilização da fantasia contratransferencial que vai ao encontro, se supõe, da fantasia transferencial do analisando. Essa ligação que o analista realiza sobre o discurso do paciente e sobre sua própria fantasia contratransferencial permitem supor uma dupla perspectiva de seu trabalho como presença e como ausência, na medida em que realiza, ao mesmo tempo, uma articulação com seu próprio pensamento. $\mathrm{O}$ interjogo entre presença $\mathrm{e}$ ausência, permite observar a criação de uma relação potencial e da posição do 
analista como terceiro. A importância dessa consideração para Green é que para ele não existem relações duais, porque sempre algum nexo estabelece a possibilidade de áreas de reunião e de separação nestas relações. Desta forma, destacamos essa postulação a fim de enfatizar a fantasia contratransferencial como um importante elemento da escuta neste momento em que os estímulos visuais estão diminuídos.

A escuta, considerada desde a perspectiva do analista como um terceiro, aliada à utilização da fantasia contratransferencial e a capacidade de devaneio são proporcionadas e, ao mesmo tempo, precisam estar contidas pelo enquadre analítico. Entende-se por enquadre o conjunto de condições de possibilidades requeridas para o exercício de uma análise, o que compreende as disposições materiais que regulam as relações entre a dupla analítica (pagamento, frequência, duração, etc) e estas disposições são fixadas, desde o início, através do que se chama o contrato. O dispositivo inclui também a regra fundamental que regulamenta a relação entre ambos: a associação livre e a atenção flutuante. $O$ trabalho do enquadre, nesta técnica que utilizamos hoje, continua mantido, e, em nossa opinião, ele parte do estabelecimento de um contrato, desde o início deste novo processo, para que as premissas da análise se efetuem e possam nortear e conter a escuta através da utilização dos elementos técnicos que mencionamos acima.

Além disso, frente às modificações que precisam ser feitas no enquadre atualmente e tendo em vista que as únicas variações aceitáveis da análise clássica são aquelas que permitem a criação de condições ótimas para a simbolização, entendemos como Green (2012, p. 28): "As variações do enquadre (e da técnica em geral) tem um sentido preciso: é de criar as condições de possibilidade para o trabalho de representação e para o funcionamento da matriz dialógica". Com isso, destacamos que o enquadre definido espacial e temporalmente é o que possibilita transformar a potencialidade inata, na medida em que a linguagem e o afeto permanecem também neste novo formato, e as condições mínimas de simbolização estão mantidas, desde que o analista seja o guardião do enquadre. Assim, se é este último que garante que o processo analítico ocorra e se as condições do setting estão modificadas pela virtualidade do atendimento, tornase necessário que o enquadre esteja internalizado no analista. A noção de enquadre interno, descrita por Green (2012), é uma matriz simbólica que possui 
uma abertura virtual, pois parte da experiência de reconhecimento do próprio inconsciente como acolhimento da alteridade interna radical.

Finalizando esse pequeno percurso sobre a técnica, entendemos que neste novo formato, onde são exigidas importantes modificações na escuta, no enquadre, na prioridade da palavra e da contratransferência, o trabalho realizado tem potencialidade para vir a ser analítico. Na dependência de que o analista por meio do seu enquadre interno se deixe afetar e trabalhe no sentido do desbloqueio e na efetividade da comunicação entre o mundo psíquico do paciente e o seu próprio.

As inquietações que emergem a partir do cenário atual evidenciam a necessidade de repensarmos os fundamentos teóricos e técnicos que potencializam a escuta, mantendo em constante movimento o fazer analítico. Logo, buscamos nas palavras de Green (2017) o que entendemos ser um dos elementos imprescindíveis frente aos desafios atuais da psicanálise:

(...) esta evolução inevitável é, em certa forma saudável, já que nos obriga a interrogar-nos sobre nós mesmos, sobre o que pensamos, sobre o que fazemos, o que não está isento de riscos, evidentemente, mas abre uma eleição entre a morte e a possibilidade de um renascimento (p. 42).

\section{Referências}

Freud, S. (1989). A dinâmica da transferência. In S. Freud, Edição standard brasileira das obras psicológicas completas de Sigmund Freud (Vol. 12, pp.131143) Rio de Janeiro: Imago. (Trabalho original publicado em 1912).

Green, A. (2001). La capacidad de ensoñación y el mito etiológico. In A. Green. La nueva clínica psicoanalítica y la teoría de Freud: aspectos fundamentales de la locura privada (pp. 157-178). Buenos Aires: Amorrortu.

Green. A. (2008). Espacio potencial en psicoanálisis. El objeto en el encuadre. In A. Green, De locuras privadas (2ed, pp. 300-325). Buenos Aires: Amorrortu. Green. A. (2012). La clínica contemporánea y el encuadre interno del analista. Diálogo de Fernando Urribarri con Andre Green. Revista de Psicoanálisis de la Associación Psicoanalítica Argentina, LXIX, n.1, 25-39. 
Green. A (2017). El encuadre psicoanalítico. Su interiorización en el analista y su aplicación en la práctica. In: A. Green, La clínica psicoanalítica contemporánea (pp. 41-68). Buenos Aires: Amorrortu 